\title{
(a) OPEN ACCESS \\ A possible Guillain-Barré syndrome/transverse myelitis overlap syndrome after recent COVID-19
}

\author{
Riyadh Alrubaye, ${ }^{1}$ Vijayamala Bondugula, ${ }^{2}$ Vidya Baleguli, ${ }^{3}$ Rosemary Chofor ${ }^{4}$
}

\begin{abstract}
- Additional supplemental material is published online only. To view, please visit the journal online (http://dx. doi.org/10.1136/bcr-2021 246967)
\end{abstract}

${ }^{1}$ Department of Hospital Medicine/Internal Medicine Residency Program, Northeast Georgia Health System Inc, Gainesville, Georgia, USA ${ }^{2}$ Department of Neurology, Northeast Georgia Health System Inc, Gainesville, Georgia, USA

${ }^{3}$ Department of GME/Internal Medicine, Northeast Georgia Health System Inc, Gainesville, Georgia, USA

${ }^{4}$ Department of GME/Internal Medicine Residency Program, Northeast Georgia Health

System Inc, Gainesville, Georgia, USA

\section{Correspondence to}

Dr Riyadh Alrubaye;

ralrubaye@gmail.com

Accepted 11 January 2022

Check for updates

(c) BMJ Publishing Group Limited 2022. Re-use permitted under CC BY-NC. No commercial re-use. See rights and permissions. Published by BMJ.

To cite: Alrubaye $R$ Bondugula V, Baleguli V, et al. BMJ Case Rep

2022:15:e246967.

doi:10.1136/bcr-2021

246967

\section{SUMMARY}

Neurological manifestations are common in SARSCoV-2 infection, including life-threatening acute muscle weakness, due to neuromuscular disorders such as acute transverse myelitis (TM) and Guillain-Barré syndrome (GBS). These syndromes can rarely coexist and present as an overlap syndrome. Here, we report a patient who developed acute symmetrical proximal lower limb weakness 5 days after diagnosis of COVID-19. GBS was diagnosed due to the presence of motor signs, albumin-cytological dissociation in cerebrospinal fluid examination and axonal damage according to nerve condition tests. However, abnormal areas on MRI of the thoracic spine and lack of improvement with intravenous immunoglobulin supported a diagnosis of TM. Therefore, a possible overlap between GBS and TM was established. To our knowledge, this is the third case report of GBS/ TM overlap syndrome after COVID-19. The patient's full and rapid recovery with intravenous corticosteroids and plasmapheresis supports our diagnosis.

\section{BACKGROUND}

COVID-19, caused by the virus SARS-CoV-2, has quickly spread worldwide since December 2019, with more than 250 million confirmed cases reported by the WHO in November 2021. The pandemic has continued to hammer hospitals with increasing numbers of cases, with broad impacts in limiting access to certain procedures and imaging that are routinely performed under regular circumstances.

Initially, the main symptoms of COVID-19 reported in late 2019 were respiratory symptoms; however, a wide range of acute neurological manifestations associated with COVID-19 have been reported in 2020 and 2021, ${ }^{1}$ with both the peripheral and the central nervous systems potentially affected. $^{23}$

Guillain-Barré syndrome (GBS) is an acute inflammatory demyelinating polyradiculopathy that classically presents with ascending weakness, areflexia/hyporeflexia and sensory involvement. ${ }^{4}$ GBS is usually attributed to the production of antibodies that attack myelin protein in response to various infections, including SARS-CoV-2 infection. $^{56}$

Acute transverse myelitis (TM) is an inflammatory disease of the central nervous system that mostly affects the paediatric population and is also triggered by an immune-mediated response to infection. The classical diagnostic criteria include back pain with acute weakness of the limbs, sensory deficit and autonomic dysfunction, along with abnormal changes on MRI. ${ }^{7}$ There are very few case reports of TM in patients with COVID-19 as compared with such reports for GBS. ${ }^{23}$

Since TM and GBS are both immune-mediated inflammatory diseases, it is possible for the two disorders to be concurrent, which is referred to as GBS/TM overlap syndrome. Herein, we report a case of GBS/TM overlap syndrome after COVID19, which was initially considered to be only GBS, highlighting the importance of a differential diagnosis of this rare comorbidity during the pandemic with potentially limited imaging resources.

\section{CASE PRESENTATION}

A 72-year-old man was diagnosed with COVID-19 in the emergency department. He was administered $700 \mathrm{mg}(7 \mathrm{mg} / \mathrm{kg})$ of intravenous bamlanivimab and was discharged with oral dexamethasone $(6 \mathrm{mg}$ daily). Five days later, he returned because of worsening generalised weakness, severe back and leg pain, constipation, urine retention and multiple ground-level falls. He denied any sensory loss or visual disturbances.

On examination, the patient was alert and oriented to person, place and time. Vital signs were within normal limits, with blood oxygen saturation of $98 \%$ breathing ambient air. His neurological assessment was notable for anisocoria, the left larger than the right (from previous injury), with the left being non-reactive. Other cranial nerves were intact, including the facial nerve. Motor examination using the Medical Research Council Manual Muscle Testing scale showed normal muscle power in the upper extremities. However, he had bilateral proximal lower extremity weakness with power of $1 / 5$ and bilateral distal lower extremity with power of $4 / 5$. Deep tendon reflexes were hypoactive in the upper extremities and absent in the lower limbs. The patient had normal muscle tone and no tremor, and fine coordination in the hands was intact. His gait was not assessable, as he was unable to bear weight. Flexor planter responses were present bilaterally. Neurosensory assessment showed intact light touch, temperature and vibration sensation in the hands and feet.

\section{INVESTIGATIONS}

Laboratory testing revealed no significant abnormalities, including normal antinuclear antibody and vitamin $B_{12}$ levels. Chest radiograph showed bilateral interstitial infiltrates, which were unchanged from 5 days previously.

Cerebrospinal fluid (CSF) analysis showed albumin-cytological dissociation with elevated 

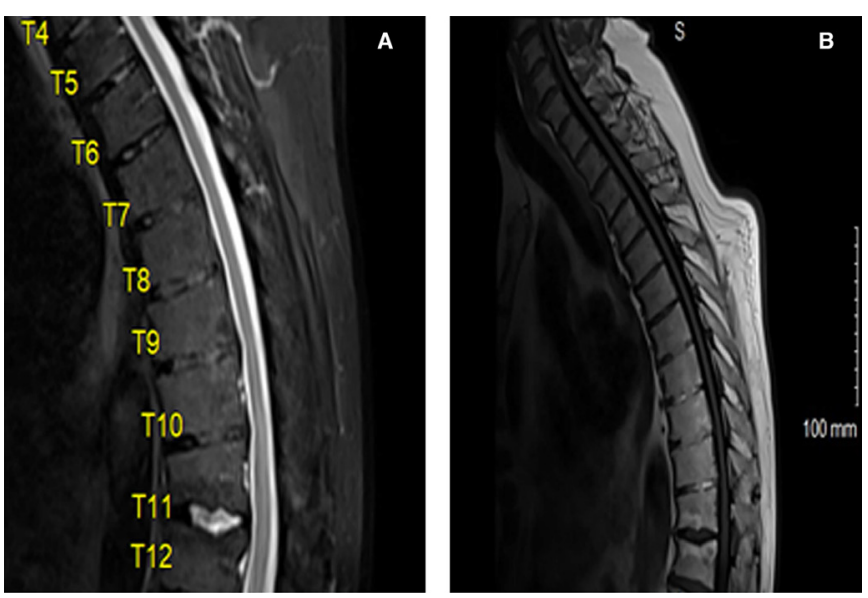

Figure $1 \mathrm{MRI}$ of the patient's thoracic spine. (A) Sagittal T1 sequence of the thoracic spine. (B) Sagittal STIR (Short Tau Inversion Recovery) sequence of the thoracic spine with minimal signal enhancement, possibly secondary to thick sagittal cuts. No significant canal stenosis or paravertebral mass is evident at the thoracic level.

protein of $211 \mathrm{mg} / \mathrm{dL}$, white cell count of 2 cell/L, normal glucose concentration and no oligoclonal bands. Routine bacterial and fungal culture and Gram stain were negative. Serological tests of the CSF were negative for cytomegalovirus, Epstein-Barr virus, venereal disease research laboratory, herpes simplex virus and SARS-CoV-2, and the paraneoplastic and autoimmune CSF panel were normal.

Whole-spine MRI sagittal sections with gadolinium did not show signal changes in the spinal cord (figure $1 \mathrm{~A}$ and $\mathrm{B}$ ) owing to some technical difficulties. However, thoracic axial spinal MRI T2-weighted images showed abnormal T2-hyperintense signals within the central thoracic spinal cord, extending from T7-T8 inferiorly to T11 and T12 (figure 2A and B) with multiple old canal stenoses at the cervical and lumbar levels and lack of root enhancement.

Nerve conduction analysis was performed with some technical difficulties due to resource restrictions associated with the COVID-19 pandemic, which showed decreased conduction velocities and decreased amplitudes, suggesting acute motor axonal neuropathy.
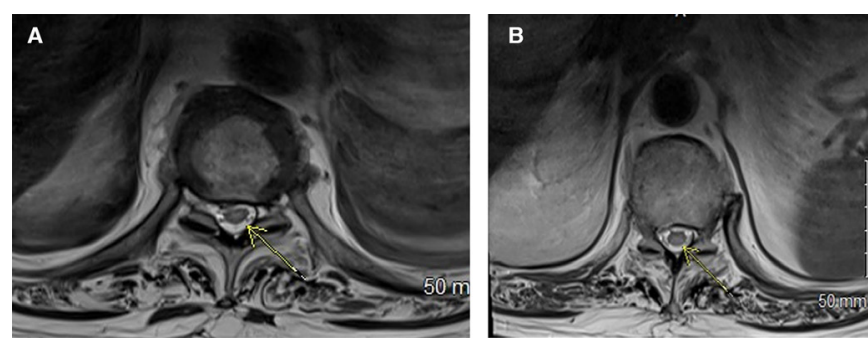

Figure $2 \mathrm{MRI}$ of the patient's thoracic spine. T2 sequence, consecutive transverse slices at the level of (A) T9 and (B) T-10, showing increased signal intensity within the central portion of the spinal cord (yellow arrow).

\section{DIFFERENTIAL DIAGNOSIS}

The possible differential diagnoses for the 72-year-old man with acute proximal lower limb weakness and areflexia after COVID-19 include acute inflammatory demyelinating polyneuropathy and TM.

Initially, we considered GBS (possibly motor variants) as the principal diagnosis, as the patient had sudden onset of lower limb weakness and areflexia. By contrast, acute flaccid weakness, back pain, autonomic dysfunction and hyperintense T2 MRI signals from T7 to T12 indicated a possible diagnosis of TM.

We believed that the patient's neuromuscular disorder was mostly secondary to COVID-19. We investigated whether bamlanivimab could be a factor; however, his symptoms started before he was administered bamlanivimab and we found little information regarding the adverse effects of bamlanivimab in the literature.

\section{TREATMENT}

Based on the patient's clinical features, we initially decided to administer intravenous immunoglobulin (IVIG) for possible GBS. However, the possibility of TM concurrency was subsequently entertained based on the worsening of both motor functions and urinary retention according to abnormal spinal images. Intravenous corticosteroid was administered at a dose of $1000 \mathrm{mg}$ daily for 5 days as of day 6 from the admission date (figure 3). Surprisingly, the patient showed significant improvement in right hip movement, with improvement in right lower proximal muscle power from 0 to 4 ; however, the power in his left hip muscles remained at 0 . Based on this partial recovery,

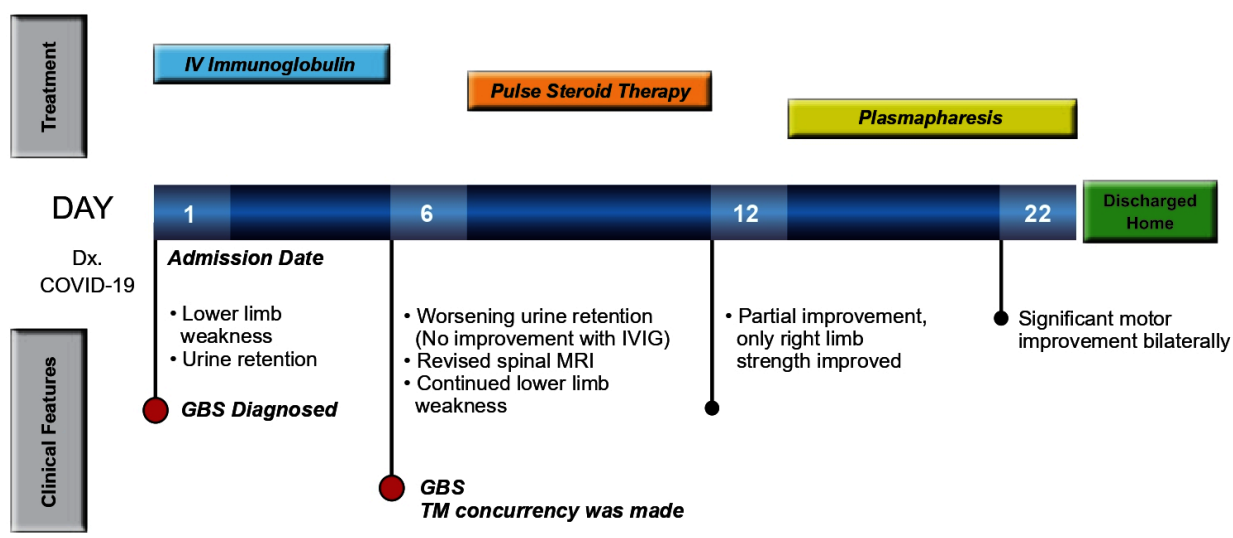

GBS = Guillian-Barré Syndrome

$\mathrm{TM}=$ Transverse Myelitis

(C) Riyadh Alrubaye 2021

Figure 3 The timeline of the case, including the treatments administered from the admission date to discharge. 
the patient was administered plasmapheresis from day 12 for five alternative sessions, which remarkably improved his left hip movement (figure 3).

\section{OUTCOME AND FOLLOW-UP}

The patient was discharged on day 22 after significant recovery. The patient was able to walk after five sessions of plasmapheresis and was discharged without the need for rehabilitation. The patient's back and leg pain resolved, and he went back to his routine life within 1 week of discharge.

\section{DISCUSSION}

The concurrency of GBS and TM (ie, GBS/TM overlap syndrome) represents a rare paradox that typically affects children and young adults more frequently than elderly patients. ${ }^{89}$ The clinical features of GBS/TM overlap syndrome can include GBS elements such as acute flaccid paralysis with hyporeflexia and TM elements such as pyramidal signs, sphincter dysfunction and sensory level. ${ }^{8}$ It is critical to note that the presence of both sensory level and sphincter dysfunction suggests the concurrency of TM in the overlap syndrome. ${ }^{8}$ Albumin-cytological dissociation (elevated CSF protein and normal cell count) with an increased $\operatorname{IgG}$ index is a non-specific CSF finding. However, two practical measures are useful to evaluate the concurrency of GBS and TM: abnormal electrophysiological findings and the presence of a central T2-hyperintense thoracic spinal cord signal in MRI. ${ }^{9} 10$

Based on a review of the literature, the majority of reported cases of GBS/TM overlap syndrome have been attributed to infections such as acute viral illness, influenza, Mycoplasma, Legionella, Bartonella and Zika virus. ${ }^{8}{ }^{81} 12$ Two previous cases of overlap syndrome after SARS-CoV-2 infection have been reported: one was a paediatric case ${ }^{13}$ and the other was in a 40 -year-old man. ${ }^{14}$ In the latter case, the patient presented with upper respiratory symptoms followed by lower limbs weakness, with mild COVID-19 findings determined by high-resolution computed chest tomography despite a negative SARS-CoV-2 PCR test. The initial diagnosis was TM based on cervical spine MRI findings; however, lack of improvement on steroid therapy necessitated CSF analysis, which showed albuminocytological dissociation, and nerve conduction analysis, which showed acute sensory and motor axonal neuropathy, a variant form of GBS that eventually improved with plasmapheresis. ${ }^{14}$ Sporadic cases of vaccine-induced GBS/TM overlap syndrome have also been reported. ${ }^{15}$ Finally, immunotherapy-related neurological disorders account for $1 \%-5 \%$ of all immune medication side effects. ${ }^{16}$ Both TM and GBS have been separately reported in some case reports after administration of nivolumab or pembrolizumab but their concurrency has not been reported in association with immune checkpoint inhibitors. ${ }^{17}$

Owing to its rarity, the treatment for GBS/TM overlap syndrome has not been well studied. IVIG and plasmapheresis can be effective for GBS, whereas intravenous corticosteroid is typically the initial treatment for TM. Therefore, based on a review of 23 cases, Guo and $\mathrm{Zhang}^{8}$ concluded that the combination of IVIG and intravenous corticosteroids had the most favourable outcome.

Several technical and clinical factors can contribute to missing the concurrency of TM in a case of GBS induced by COVID-19. In particular, it has been difficult to perform both MRI and nerve conduction analysis during the pandemic. ${ }^{6}$ Moreover, neuropathy or myopathy associated with a critical illness in the setting of long-term mechanical ventilation can mimic overlap syndrome. ${ }^{1}$ Despite these obstacles, a detailed history and subsequent physical examinations can help to make the appropriate diagnosis.

\section{Patient's perspective}

Initially they diagnosed me with COVID and when I got home my legs just gave away and I had severe back pain which led me to come back to the hospital. I lost use of my hip and all my muscles just shut down. After steroid and plasma treatment I started to feel great. Am currently doing great. Am walking and working all day. I want to compliment the doctors and nurses for their help.

Learning points

- Guillain-Barré syndrome (GBS)/transverse myelitis (TM) overlap syndrome should be suspected in patients presenting with severe back pain, motor weakness, areflexia, sensory level and urine retention.

- TM concurrent with GBS caused by COVID-19 can be initially missed secondary to the limited MRI use during the pandemic. This can delay the patient's recovery and increase the length of stay.

- Intravenous steroid and plasmapheresis showed a better outcome in our case than intravenous immunoglobulin and steroids.

- Due to limited cases and reviews, further study of this overlap syndrome may help to improve the diagnostic and therapeutic approach.

Acknowledgements We thank editage.com for the editing service of this manuscript.

Contributors VB and RC wrote the manuscript. RA supervised this work, revised and modified the manuscript. VB revised the manuscript.

Funding The authors have not declared a specific grant for this research from any funding agency in the public, commercial or not-for-profit sectors.

Competing interests None declared.

Patient consent for publication Obtained.

Provenance and peer review Not commissioned; externally peer reviewed.

Open access This is an open access article distributed in accordance with the Creative Commons Attribution Non Commercial (CC BY-NC 4.0) license, which permits others to distribute, remix, adapt, build upon this work non-commercially, and license their derivative works on different terms, provided the original work is properly cited and the use is non-commercial. See: http://creativecommons.org/ licenses/by-nc/4.0/.

Case reports provide a valuable learning resource for the scientific community and can indicate areas of interest for future research. They should not be used in isolation to guide treatment choices or public health policy.

\section{REFERENCES}

1 Galassi G, Marchioni A. Facing acute neuromuscular diseases during COVID-19 pandemic: focus on Guillain-Barré syndrome. Acta Neurol Belg 2020;120:1067-75.

2 Mao L, Jin $\mathrm{H}$, Wang M, et al. Neurologic manifestations of hospitalized patients with coronavirus disease 2019 in Wuhan, China. JAMA Neurol 2020;77:683-90.

3 Montalvan V, Lee J, Bueso T, et al. Neurological manifestations of COVID-19 and other coronavirus infections: a systematic review. Clin Neurol Neurosurg 2020;194:105921.

4 Sriwastava S, Kataria S, Tandon M, et al. Guillain Barré syndrome and its variants as a manifestation of COVID-19: a systematic review of case reports and case series. J Neurol Sci 2021;420:117263.

5 Carrillo-Larco RM, Altez-Fernandez C, Ravaglia S, et al. COVID-19 and Guillain-Barre syndrome: a systematic review of case reports. Wellcome Open Res 2020;5:107.

6 Abu-Rumeileh S, Abdelhak A, Foschi M, et al. Guillain-Barré syndrome spectrum associated with COVID-19: an up-to-date systematic review of 73 cases. J Neurol 2021;268:1133-70.

7 Transverse Myelitis Consortium Working Group. Proposed diagnostic criteria and nosology of acute transverse myelitis. Neurology 2002;59:499-505.

8 Guo F, Zhang Y-B. Clinical features and prognosis of patients with Guillain-Barré and acute transverse myelitis overlap syndrome. Clin Neurol Neurosurg 2019;181:127-32. 
9 Mao Z, Hu X. Clinical characteristics and outcomes of patients with Guillain-Barré and acquired CNS demyelinating overlap syndrome: a cohort study based on a literature review. Neurol Res 2014;36:1106-13.

10 Goh C, Desmond PM, Phal PM. Mri in transverse myelitis. J Magn Reson Imaging 2014;40:1267-79.

11 Tolunay O, Çelik T, Çelik Ümit, et al. Concurrency of Guillain-Barre syndrome and acute transverse myelitis: a case report and review of literature. Korean J Pediatr 2016:59:S161-4.

12 Román GC, Anaya J-M, Mancera-Páez Óscar, et al. Concurrent Guillain-Barré syndrome, transverse myelitis and encephalitis post-Zika: a case report and review of the pathogenic role of multiple arboviral immunity. J Neurol Sci 2019;396:84-5.

13 Khera D, Didel S, Panda S, et al. Concurrent longitudinally extensive transverse myelitis and Guillain-Barré syndrome in a child secondary to COVID-19 infection: a severe neuroimmunologic complication of COVID-19. Pediatr Infect Dis J 2021;40:e236-9.
14 Inam SHA, Riaz B, Abdullah M. Acute transverse myelitis (ATM) and Guillain-Barre syndrome (GBS) overlap syndrome in a COVID-19 patient: a case report. Annal Int Med Dent Res 2021 https://pesquisa.bvsalud.org/global-literature-on-novelcoronavirus-2019-ncov/resource/en/covidwho-1116203

15 Sato N, Watanabe K, Ohta K, et al. Acute transverse myelitis and acute motor axonal neuropathy developed after vaccinations against seasonal and $2009 \mathrm{~A} / \mathrm{H} 1 \mathrm{~N} 1$ influenza. Intern Med 2011;50:503-7.

16 Knauss S, Ginesta Roque L, Hühnchen P, et al. [Neurological side effects of checkpoint inhibitors]. Nervenarzt 2019;90:138-47.

17 Manam R, Martin JL, Gross JA, et al. Case reports of pembrolizumab-induced acute inflammatory demyelinating polyneuropathy. Cureus 2018;10:e3371.

Copyright 2022 BMJ Publishing Group. All rights reserved. For permission to reuse any of this content visit https://www.bmj.com/company/products-services/rights-and-licensing/permissions/

BMJ Case Report Fellows may re-use this article for personal use and teaching without any further permission.

Become a Fellow of BMJ Case Reports today and you can:

- Submit as many cases as you like

- Enjoy fast sympathetic peer review and rapid publication of accepted articles

- Access all the published articles

Re-use any of the published material for personal use and teaching without further permission

Customer Service

If you have any further queries about your subscription, please contact our customer services team on +44 (0) 2071111105 or via email at support@bmj.com.

Visit casereports.bmj.com for more articles like this and to become a Fellow 